\title{
COMPARISON OF EXPRESSION OF E-CADHERIN IN ORAL PSEUDOEPITHELIOMATOUS HYPERPLASIA AND ORAL SQUAMOUS CELL CARCINOMA
}

\author{
Ayesha Mukhtar Awan', Iram Naz², Muhammad Khurram Mahmood ${ }^{3}$, Hafeez Uddin ${ }^{4}$ \\ ${ }^{1}$ Department of Oral Pathology, Armed Forces Institute of Pathology, Rawalpindi, ${ }^{2}$ Department of Oral \\ Pathology, Islamabad Medical and Dental College, Islamabad, ${ }^{3}$ Department of Pharmacology and \\ Therapeutics, HBS Medical and Dental College, Islamabad, ${ }^{4}$ Department of Histopathology, Armed Forces \\ Institute of Pathology, Rawalpindi, Pakistan
}

\begin{abstract}
Background: Pseudo-epitheliomatous Hyperplasia (PEH) is a benign proliferation of epithelium occurring in response to various neoplastic lesions, infections and inflammatory processes. It can be mistaken especially in small biopsies for an invasive oral squamous cell carcinoma (OSCC). The objective of this study was to determine the expression and comparison of immunohistochemical marker E-cadherin in OSCC and PEH lesions.

Materials \& Methods: This cross-sectional study was conducted in Department of Histopathology, Armed Forces Institute of Pathology, Rawalpindi, Pakistan from January 2013 to March 2016. 60 paraffin embedded cases, 30 each of PEH and OSCC were retrieved and stained with haematoxylin and eosin. They were then immune-stained with E-cadherin and expression evaluated and compared in two lesions by histopathologist. Age, sex, site of lesion and E-cadherin expression were variables. Age was described by mean and SD and other variables as frequency and percentages.

Results: Mean age of OSCC group was $60.1 \pm 17.3$ years and PEH group $52.7 \pm 16.6$ years. OSCC group included $16(53.33 \%)$ men and 14 (46.67\%) women. PEH group included 18 (60\%) men and 12 (40\%) women. In OSCC group, site of lesion was buccal mucosa $12(40 \%)$ cases, gingiva $10(33.3 \%)$, tongue $7(23.3 \%)$ and floor of mouth 1 (3.4\%) case. In PEH group, site of lesion was buccal mucosa 12 (40\%) cases, tongue 11 (36.67\%), gingiva 6 $(20 \%)$ and palate $1(3.3 \%)$ case.
\end{abstract}

The expression of E-cadherin was negative in all 30 cases of OSCC and positive in 29/30 (96.67\%) cases in PEH.

Conclusion: E-cadherin can be used as an ancillary marker in the differentiation of oral squamous cell carcinoma and pseudo-epitheliomatous hyperplasia.

KEY WORDS: Pseudo-epitheliomatous Hyperplasia; Squamous cell carcinoma; E-Cadherins; Immunohistochemistry; Cancer biomarkers; Monoclonal antibodies.

This article may be cited as: Awan AM, Naz I, Mahmood MK, Uddin H. Comparison of expression of E-cadherin in oral pseudoepitheliomatous hyperplasia and oral squamous cell carcinoma. Gomal J Med Sci 2019 Jul-Sep; 17 (3): 70-4. https://doi.org/10.46903/gjms/17.03.1967

\section{INTRODUCTION}

Oral Squamous Cell Carcinoma (OSCC) is an aggressive lesion that arises from the squamous epithelium of oral cavity. ${ }^{1}$ Microscopically the epithelial cells exhibit squamous differentiation marked by the

\section{Corresponding Author:}

Dr. Ayesha Mukhtar Awan

Registrar, Department of Oral Pathology

Armed Forces Institute of Pathology

Rawalpindi, Pakistan

E-mail: ayeshaawan509@gmail.com

Date Submitted: 23-02-2019

Date Revised: 17-04-2019

Date Accepted: 27-05-2019 presence of keratin pearls and intercellular bridges. ${ }^{2}$ Its occurrence is high in developing countries, posing a major health problem. ${ }^{3-4}$ It is the tenth most common cancer in Pakistan. ${ }^{5}$ Despite improved management strategies developed in the last thirty years, its survival rate has not changed. ${ }^{6}$ This might have resulted due to delay in its detection or its susceptibility of local recurrence and metastasis. ${ }^{7}$

Pseudo-epitheliomatous hyperplasia (PEH) is a benign proliferation of epithelium occurring in response to various disorders, including neoplastic lesions, infections and inflammatory processes. ${ }^{8}$ Histologically it is represented as exuberant overgrowth of squamous epithelium seen as extending into connective tissue in a tongue like pattern and can be mistaken 
for an invasive OSCC, especially in small biopsies. ${ }^{9}$ This becomes even more challenging to distinguish between OSCC and PEH when the rete pegs are anastomosing deep into the connective tissue and the biopsies cut are poorly oriented tangentially. ${ }^{10}$ However, the research on certain biomarkers to differentiate between PEH and OSCC is scarce and no study so far has been conducted in our population to evaluate the role of immunohistochemical proteins in these lesions.

E-Cadherin is a transmembrane glycoprotein found on the surface of the epithelial cells having a molecular weight of $120-\mathrm{kDa}{ }^{11}$ Loss of E-Cadherin fragment causes breakage of adherent junctions which results in detachment of epithelial cells making them vulnerable for invading the deeper tissues in oral cancers. ${ }^{12} \mathrm{E}$-cadherin has frequently been studied as a potential cancer biomarker and is hypothesized that its expression might be useful in differentiating OSCC from PEH. ${ }^{10}$ This is essential as erroneous diagnosis of malignancy results in radical surgery, treatment related morbidity and can even have fatal consequences.

The objective of this study was to determine the expression and comparison of immunohistochemical marker E-cadherin in OSCC and PEH lesions.

\section{MATERIALS AND METHODS}

\section{Specimen}

This cross-sectional study was conducted in the Department of Histopathology, Armed Forces Institute of Pathology (AFIP), Rawalpindi, Pakistan from January 2013 to March 2016. The proposal of the study was approved by the Institutional Ethical Review Committee. Two samples of paraffin embedded cases, 30 each of PEH and OSCC were retrieved from the archives of the Armed Forces Institute of Pathology (AFIP), Rawalpindi. Adequacy was ensured. Scanty and autolysed tissues were not included.

\section{Immunohistochemistry}

Samples were cut into $4-\mu \mathrm{m}$ sections and stained with hematoxylin and eosin. They were evaluated by the same experienced pathologist, reviewed and graded according to Anneroth's classification. ${ }^{13}$ The tissue sections were immuno-stained with monoclonal antibodies against E-cadherin (1:100, catalogue No: 081223; Invitrogen, USA) by fixing sections in $10 \%$ buffered formalin. Later these were placed on glass slides and dried overnight at $37^{\circ} \mathrm{C}$. Tissue sections from deparaffinized slides were mounted on HistoGrip coated slides, washed with distilled water 3 times for 2 minutes each. Then Pyrex glass beaker containing $500 \mathrm{ml}$ of $0.01 \mathrm{M}$ citrate buffer was placed on a hot plate and the solution was heated till it boiled. Slides were put on a slide rack and placed in the beaker with boiling solution and kept boiling for 15 minutes. After heating, slides were allowed to cool at room temperature for at least 20 minutes.
They were then rinsed with Phosphate Buffered Saline (PBS) and submerged in peroxidase quenching solution and rinsed again with PBS. They were applied with serum blocking solution and later with primary antibody and incubated for 30-60 minutes at room temperature and rinsed again with PBS. A secondary antibody was then applied and incubated for 10 minutes at room temperature and rinsed again with PBS. Enzyme conjugate was applied and incubated for 10 minutes at room temperature and rinsed again with PBS. Chromogen was finally applied, incubated for 5-10 minutes at room temperature and rinsed with PBS.

\section{Scoring criteria}

Scoring for E-cadherin was done according to the scoring criteria proposed by You et al. ${ }^{14}$ Immunoreactivity of E-cadherin was evaluated by calculating percentage of positive stained cells; staining pattern $(P) \times$ staining intensity (I); (Immunoreactivity $=\mathrm{Px} I$ ).

Normal oral mucosa was used as a positive control to ensure homogenous accurate and reproducible staining and rated as 1 (weak), 2 (moderate) and 3 (strong). If the intensity of E-cadherin staining in tumour cells was the same as in normal epithelial cells, then it was recorded as 3 (strong). If it was recognizable but weaker than in normal cells, it was recorded as 2 (moderate). If $\leq 50 \%$ cells were stained, then it was considered as 1 (weak) staining.

The staining pattern of E-cadherin was categorized into four groups: negative as zero, $\leq 50 \%$ of cells as $1,51-75 \%$ of cells as 2 and $>75 \%$ of cells were scored as 3. Percentages of stained cells (staining pattern) were calculated by arbitrary counting of cells by considering 10 consecutive microscopic high power fields. Percentages of E-cadherin positive cells were calculated by dividing stained cells with total number of cells multiplied by 100 . The immunoreactivity of E-cadherin was divided into two groups based on staining intensity and staining pattern scores; a score of 0-6 was defined as negative and a score of $>6$ was defined as positive immunoreactivity.

\section{Data Collection \& Analysis Plan}

Age in years and sex were two demographic variables, while site of the lesion and E-cadherin expression (positive/ negative) were research variables. Age in years was measured on ratio (numeric) scale and was described by mean, SD, minimum, maximum and range. The other variables were measured on nominal scale and were described as frequency and percentages.

\section{RESULTS}

The mean (SD) age of 30 cases of oral squamous cell carcinoma (OSCC) was $60.1 \pm 17.3$ (21-95) with a range of 74 years. For pseudo-epitheliomatous hyperplasia $(\mathrm{PEH})$, it was $52.7 \pm 16.6$ (13-82) with a 
range of 69 years.

OSCC group included 16 men (53.33\%) and 14 women (46.67\%). PEH group included 18 men (60\%) and 12 women (40\%).

In OSCC group, site of the lesion was buccal mucosa in $12(40 \%)$ cases, followed by gingiva in 10 (33.3\%), tongue in $7(23.3 \%)$ and floor of the mouth in $1(3.4 \%)$ case. In PEH group, site of the lesion was buccal mucosa in $12(40 \%)$ cases, followed by tongue in $11(36.67 \%)$, gingiva in $6(20 \%)$ and palate in $1(3.3 \%)$ case.

All the thirty biopsies of OSCC showed a negative expression for E-cadherin; $83.4 \%$ showed weak while $16.6 \%$ had moderate staining intensity. On evaluating the staining pattern of E-cadherin, $24(80 \%)$ OSCC showed a score of 1 and the rest $6(20 \%)$ scored as 2. Immunoreactivity to E-cadherin was designated with a score of 1 in $24(80 \%)$ cases, followed by score of 2 in $2(6.67 \%)$ cases and score of 4 in $4(13.3 \%)$ cases of OSCC.

However, the expression of E-cadherin was seen positive in 29 of 30 (96.7\%) cases of PEH (Photomicrograph 1); all of them showed a strong staining intensity for E-cadherin and a score of 3 according to the staining pattern. The only one (3.3\%) negative case had a moderate staining intensity and a score of 1 according to staining pattern. Immunoreactivity to E-cadherin was designated with a score of 9 in $29(96.7 \%)$ cases and a score of 2 in $1(3.3 \%)$ case of PEH.

\section{DISCUSSION}

OSCC is one of the most prevailing worldwide malignant tumours of the head and neck region and a leading contributor of death and morbidity. ${ }^{15}$ $\mathrm{PEH}$ on the other hand is a benign lesion which commonly involves mucous membranes and lacks typical features of malignancy like nuclear atypia and aberrant mitosis. ${ }^{16}$ The clinical data collected with histopathological report may not always be sufficient for a conclusive diagnosis especially in challenging cases. Tissue biomarkers are therefore studied as an auxiliary methods to reveal the cellular alterations present in the tumours which help in the detection of any malignancy, hence, improving prognosis and treatment modalities. ${ }^{17} \mathrm{E}$-cadherin is an important member of Cadherin family which is essential in establishing cell to cell adhesion and in maintaining the integrity of the epithelial tissue..$^{18}$ The suppression of E-cadherin expression leads to loss of cell binding that contributes to the development and progression of cancer. ${ }^{19}$

All the 30 specimens of OSCC of our study showed

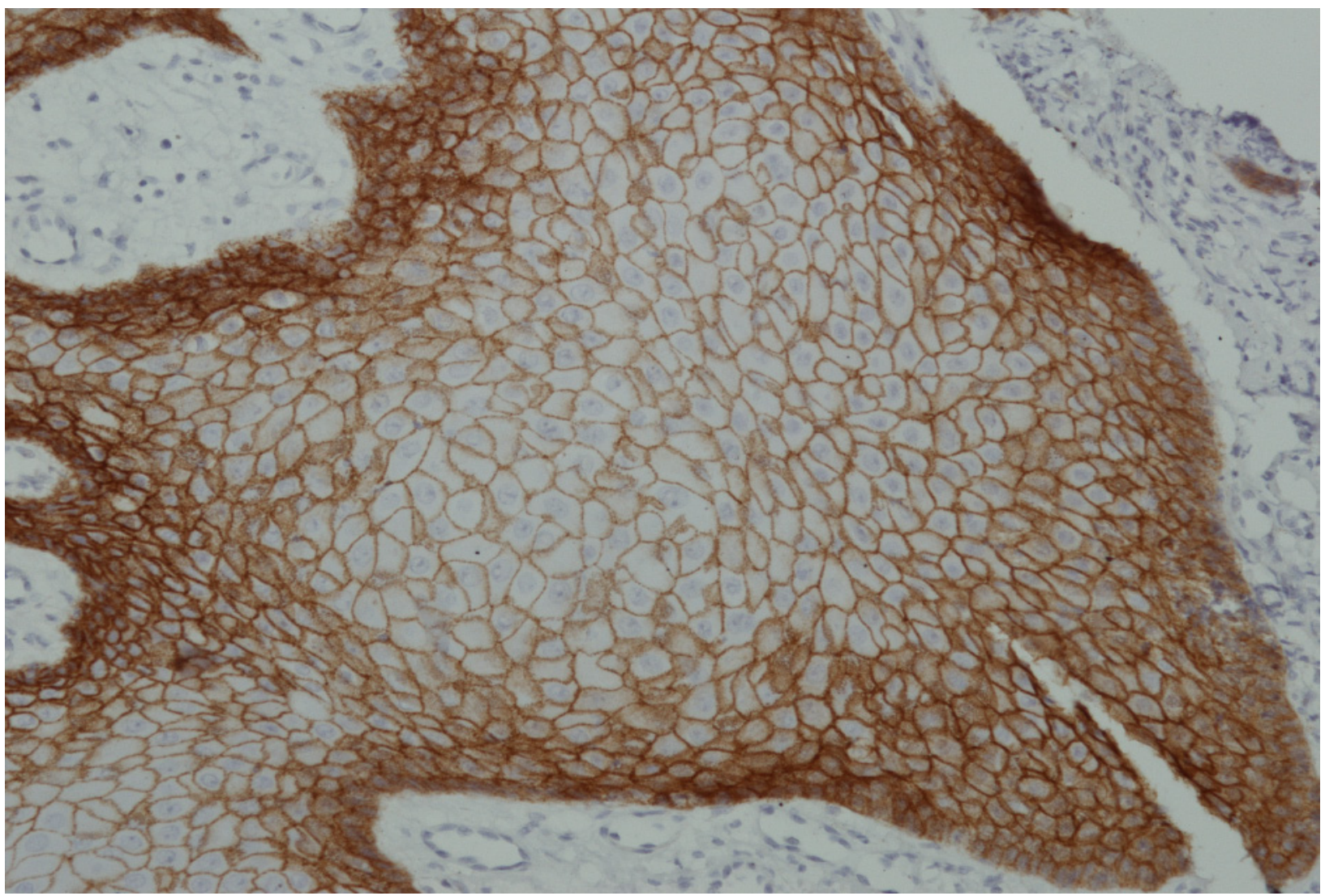

Photomicrograph 1: Strong expression of E-Cadherin in Pseudo-epitheliomatous Hyperplasia (PEH) (x40) 
negative expression for E-Cadherin. A study conducted by Zarovnaya \& Black on 16 cases of OSCC revealed its decreased staining in the invasive cells. ${ }^{12}$ Likewise a study by Sridevi et al. showed that $60 \%$ subjects showed weak, $30 \%$ mild to moderate and remaining $10 \%$ moderate to strong expression and also revealed loss of E-cadherin expression in tumour which is in agreement to our findings. ${ }^{20}$ In our study 25 of $30(83.3 \%)$ OSCC specimens showed weak staining intensity of E-cadherin while the remaining $5(16.6 \%)$ had moderate staining intensity. Another study by Liu et al. analyzed 83 tumour cases of primary OSCC with E-cadherin; 48 (58\%) exhibited positive E-cadherin expression and the rest 35 (42\%) were negative. E-cadherin expression was frequently lost at the invasive tumour front. This contradictory expression may be influenced by methodological disparities. ${ }^{21}$ Yuwanat et al. also reported a reduced expression of E-cadherin in OSCC which was statically significant and in accordance with our study. ${ }^{22}$ Contrary to OSCC, 29 of 30 cases of PEH showed positive staining with E-Cadherin and negativity in just one case. You et al. also applied E-cadherin on 29 cases of PEH and detected it in the cell membranes of $\mathrm{PEH}$ and all specimens showed preserved expression of E-Cadherin. However, its expression was reduced in the cell membranes of the neoplastic cells. The invasive tumour cells showed weak and incomplete membranous staining for E-cadherin. ${ }^{13}$

We found significant expression of E-cadherin in PEH biopsies and insignificant in OSCC. This signifies its use as an adjunct in small challenging biopsies in differential diagnosis of OSCC and PEH. Identifying and scoring of immunohistochemical $(\mathrm{IHC})$ markers play a key role in oncology. It helps in determining the type of lesion and predicting the clinical course of the disease. Due to limited resources available in our setup, we were unable to use software for scoring of tissue stains on a slide and therefore proposed the use of visual scoring and quantization to assess the staining of E- cadherin.

\section{CONCLUSION}

E-cadherin can be used as an ancillary marker in the differentiation of oral squamous cell carcinoma and pseudo-epitheliomatous hyperplasia.

Acknowledgement: We are thankful to Dr. Zafar Ali and the staff of Department of Histopathology, AFIP, Rawalpindi for all their technical assistance provided during the entire research work.

\section{REFERENCES}

1. Patel S, Ansari J, Meram A, Abdulsattar J, Cotelingam J, Coppola D, et al. Increased nicotinamide phosphoribosyl transferase and cystathionine-beta-synthase in oral cavity squamous cell carcinomas. Int J Clin Exp Pathol 2017; 10(1):702-7.

2. Shaikh AH, Mohammad T, Qureshi NR. His- topathological patterns of oral squamous cell carcinoma. Pak Oral Dental J 2014; 34(3):449-51.

3. Krishna A, Singh RK, Singh S, Verma P, Pal US, Tiwari S. Demographic risk factors, affected anatomical sites and clinicopathological profile for oral squamous cell carcinoma in a north Indian population. Asian Pac J Cancer Prev 2014; 15(16):6755-60. https://doi.org/10.7314/ APJCP.2014.15.16.6755

4. Singh MP, Kumar V, Agarwal A, Kumar R, Bhatt $\mathrm{ML}$, Misra S. Clinico-epidemiological study of oral squamous cell carcinoma: A tertiary care centre study in North India. J Oral Biol Craniofac Res 2016; 6(1):32-5. https://doi.org/10.1016/j. jobcr.2015.11.002

5. Markopoulos AK. Current aspects on oral squamous cell carcinoma. Open Dent J 2012; 6:126-30. https://doi.org/10.2174/18742106012 06010126

6. Athirajan V, Razak IA, Thurairajah N, Ghani WM, Ching HN, Yi HY, et al. High serum level of retinol and alpha-tocopherol affords protection against oral cancer in a multiethnic population. Asian Pac J Cancer Prev 2014; 15(19):8183-9. https://doi. org/10.7314/APJCP.2014.15.19.8183

7. Li G, Li X, Yang M, Xu L, Deng S, Ran L. Prediction of biomarkers of oral squamous cell carcinoma using microarray technology. Sci Rep 2017; 7:1-8. https://doi.org/10.1038/srep42105

8. Eid RA, Sawair F, Landini G, Saku T. Age and the architecture of oral mucosa. AGE 2012; 34(3):6518. https://doi.org/10.1007/s11357-011-9261-1

9. Chakrabarti S, Chakrabarti PR, Agrawal D, Somanath S. Pseudoepitheliomatous hyperplasia: A clinical entity mistaken for squamous cell carcinoma. J Cutan Aesthet Surg 2014; 7(4):232-34. https://doi.org/10.4103/0974-2077.150787

10. Mehendiratta M, Solomon MC, Boaz K, Guddattu V, Mohindra A. Clinico-pathological correlation of E-cadherin expression at the invasive tumor front of Indian oral squamous cell carcinomas: An immunohistochemical study. J Oral Maxillofac Pathol 2014; 18(2):217-22. https://doi. org/10.4103/0973-029X.140753

11. Ahmad M, Khadim M, Bukhari N. E-cadherin expression, a valuable predictor of invasiveness in histological grades of oral squamous cell carcinoma. Pak Oral Dental J 2013; 33(2):271-7.

12. Zarovnaya E, Black C. Distinguishing pseudoepitheliomatous hyperplasia from squamous cell carcinoma in mucosal biopsy specimens from the head and neck. Arch Pathol Lab Med 2005; 129(8):1032-6.

13. Bhargava A, Saigal S, Chalishazar M. Histopathological grading systems in oral squamous cell carcinoma: A review. J Int Oral Health 2010; 2(4):1-10.

14. You TK, Kim KM, Noh SJ, Bae JS, Jang KY, Chung MJ, et al. Expressions of E-cadherin, Cortactin and MMP-9 in pseudoepitheliomatous hyperplasia and squamous cell carcinoma of the 
head and neck: Their relationships with clinicopathologic factors and prognostic implication. Korean J Pathol 2012 Aug; 46(4):331-40. https:// doi.org/10.4132/KoreanJPathol.2012.46.4.331

15. Hu Y, He MY, Zhu LF, Yang CC, Zhou ML, Wang $\mathrm{Q}$, et al. Tumor-associated macrophages correlate with the clinicopathological features and poor outcomes via inducing epithelial to mesenchymal transition in oral squamous cell carcinoma. J Exp Clin Canc Res 2016; 35:1-19. https://doi. org/10.1186/s13046-015-0281-z

16. Ling YH, Zhu CM, Wen SH, Luo RZ, Li P, Cao Y, et al. Pseudoepitheliomatous hyperplasia mimicking invasive squamous cell carcinoma in extranodal natural killer/T-cell lymphoma: a report of 34 cases. Histopathology 2015; 67(3):404-9. https://doi. org/10.1111/his.12656

17. de Moraes M, Monteiro Maia CAD, de Almeida Freitas R, Galvao HC. Cell proliferation markers in oral squamous cell carcinoma. J Mol Biomark Diagn 2012; 2:1-5. S2:006. https://doi. org/10.4172/2155-9929.S2-006

18. Rajwar YC, Jain N, Bhatia G, Sikka N, Garg B, Walia E. Expression and significance of cadherins and its subtypes in development and pro- gression of oral cancers: a review. J Clin Diagn Res 2015; 9(5):ZE05-7. https://doi.org/10.7860/ JCDR/2015/11964.5907

19. Zaid KW. Immunohistochemical assessment of E-cadherin and $\square$-catenin in the histological differentiations of oral squamous cell carcinoma. Asian Pac J Cancer Prev 2014; 15(20):8847-53. https://doi.org/10.7314/APJCP.2014.15.20.8847

20. Sridevi U, Jain A, Nagalaxmi V, Kumar UV, Goyal $\mathrm{S}$. Expression of E-cadherin in normal oral mucosa, in oral precancerous lesions and in oral carcinomas. Eur J Dent 2015; 9(3):364-72. https:// doi.org/10.4103/1305-7456.163238

21. Liu LK, Jiang $X Y$, Zhou XX, Wang DM, Song $X L$, Jiang $H B$. Upregulation of vimentin and aberrant expression of E-cadherin/ - -catenin complex in oral squamous cell carcinomas: correlation with the clinicopathological features and patient outcome. Mod Pathol 2010; 23(2):213-24. https:// doi.org/10.1038/modpathol.2009.160

22. Yuwanati MB, Tupkari JV, Avadhani A. Expression of E-cadherin in oral epithelial dysplasia and oral squamous cell carcinoma: An in vivo study. J Clin Exp Invest 2011; 2(4):347-53. https://doi. org/10.5799/ahinjs.01.2011.04.0070

\section{CONFLICT OF INTEREST \\ Authors declare no conflict of interest. GRANT SUPPORT AND FINANCIAL DISCLOSURE None declared.}

\begin{tabular}{|c|c|}
\hline \multicolumn{2}{|c|}{ AUTHORS' CONTRIBUTION } \\
\hline The following authors have made subst & ial contributions to the manuscript as under: \\
\hline Conception or Design: & AMA, IN \\
\hline Acquisition, Analysis or Interpretation of Data: & AMA, IN, MKM, HU \\
\hline Manuscript Writing \& Approval: & AMA, IN, MKM, HU \\
\hline
\end{tabular}
unrestricted use, distribution \& reproduction in any medium provided that original work is cited properly. 